\title{
Analysis of the Difference between Hydraulic Fracturing and Flow Channel Fracturing
}

\author{
Mia Ferian Helmy ${ }^{1 *}$, Muhammad Zakiy Y. ${ }^{1)}$, Dinar Kaesti ${ }^{1)}$, Maulida Aulia F. ${ }^{1)}$, Anisa Novia R. \\ 1) Petroleum Engineering Department, UPN "Veteran" Yogyakarta \\ *email: mia.ferhel@gmail.com
}

\begin{abstract}
As time goes by, there will be a decline in formation productivity, as reflected in the decline in the rate of oil production from production wells. The decline in the rate of production was caused by many things such as a decrease in reservoir pressure, also formation damage. Where damage to the formation will result in a decrease in rock permeability. The decrease in rock permeability is caused by the blockage of rock pores due to the invasion of solids and drill mud filtrate, cementing, fluid fluids or previous stimulation. Besides the small rate of oil production can also be caused by the low natural permeability of rocks. With the decreasing productivity of the formation, it is necessary to make efforts to increase the productivity of the formation again, where one of them is by the method of hydraulic fracture stimulation. In this analysis, we will discuss the difference between conventional stimulation methods and flow channel fracturing. Flow channel fracturing is a fracturing process by making a network around proppant granules to form proppant pillar, so that a path is formed for the fluid to flow more easily. What distinguishes between conventional hydraulic fracturing with flow channel fracturing is the resulting fracture form, fracturing fluid injection pattern, and the amount of proppant used.
\end{abstract}

Keyword: hydraulic fracturing, flow channel fracturing

\section{INTRODUCTION}

Stimulation is the process of stimulating wells (to repair) to increase the flow of fluid in the reservoir layer that is experiencing formation damage. The stimulation process has been used to increase oil and gas production from underground reservoirs for more than forty years.

The stimulation method most often used to increase the productivity of wells that have experienced formation damage is acidification, or hydraulic fracturing.

Hydraulic fracturing operation can be done in two ways namely the conventional method and the flow channel fracturing method. The purpose of this study is to analyze the differences from conventional fracturing with fracturing flow channels.

\section{BASIC OF THEORITICAL}

\subsection{Hydraulic Fracturing}

Hydraulic fracturing is the process of making a fracture or reservoir fluid flow path to the wellbore by injecting fracturing fluid with pressure above the fracture formation pressure. Formations that undergo fracturing continue to be injected using fluid to widen the fracture that has occurred. The fracture that occurs will be propped up with proppant in the form of sand with the aim that the fracture will not close again

\subsection{Hydraulic Fracturing Equipment}

Equipment in hydraulic fracturing operations can be divided into two parts, namely equipment that is on the surface (surface equipment) and below the surface (subsurface equipment).

Surface equipment consists of:

- Fracturing Pump

- Fracturing Blender

- Mixing tank

- Fracturing Control Cabin

- Gravity Feed Sand Silo

- Laboratory Container

- $\quad$ POP off Valve

While subsurface equipment consists of:

- Drill pipe

- Packer 


\subsection{Hydraulic Fracturing Fluid}

Fracturing fluids or fracturing fluids are fluids which will be pumped at several stages, each of which has its function. Besides being used to start fracturing and expanding fractures, the fracture fluid must also be able to widen the fracture, transport and place the proppant. It also does not cause large friction in the tubing, is compatible with formations and fluids, is easy to mix, safe, and relatively inexpensive.

Fracturing fluids is one of the determining factors for the success of a hydraulic fracturing operation, so it needs to be planned. In planning the fracture fluid, it is necessary to have the right composition between base fluid, additives, and even proppants.

\subsubsection{Base Fluid}

Base fluid is a fluid with the basic ingredients in the form of water or oil. The composition used in fluid base water is water. While the composition used in oil base fluid is kerosene or diesel oil or crude oil which is compacted by the addition of napalm gel.

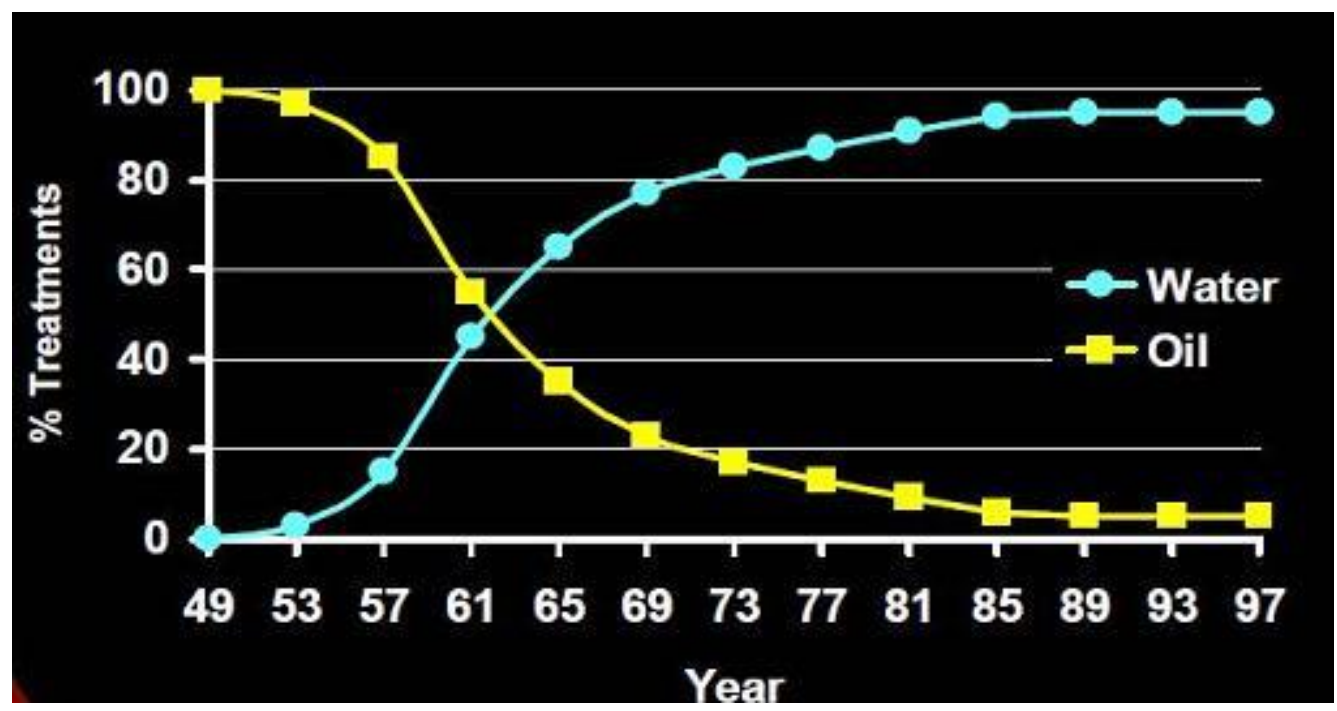

Graph 2.1. Use of Base Fluid in 1949-1997

In Graph 2.1. The plot between the base fluid used and the time of the hydraulic fracturing operation from the first year (1949) to 1997, that the initial hydraulic fracturing operation carried out by Stanoil in 1949 used an oil base fluid. Then in 1953 water base fluid began to be developed whose use has increasingly increased to defeat the use of oil-based fluid until 1997. The use of water-based fluid is more widely used compared to oil base fluid due to various considerations, namely the use of water-based fluid is more economical compared to oil base fluid. The advantages of using a waterbased fluid are: cheap, easy to obtain, available in large quantities, safe, and has no risk of burning. The drawback is: the friction is higher than oil. While fluid base oil has advantages, namely: its viscosity is higher than water so that fluid loss is low, can be resold after use, friction is lower than water. The disadvantages are: it is more expensive than water, has a risk of fire

The choice of base fluid type also needs to be adjusted to the formation, if the productive formation is a sandstone formation, water base fluid or oil-based fluid can be used. If the productive formation is a carbonate, limestone, dolomite or a formation with high solubility, use acid-based fluid will be more effective. As for productive formations with clay content, it is recommended to use oil-based fluid to overcome the decrease in permeability from the influence of clay which is sensitive to water.

\subsubsection{Additive}

In perfecting fracturing fluids, some additives are needed, including:

- Bacteriacides, to kill bacteria and reduce the rate of growth of bacterial reactions in fracturing fluids because bacteria will damage bonds which can reduce the viscosity of fracturing fluids.

- Gelling agent, to increase viscosity and proppant transportation.

- Non-emulsifying agent, serves to prevent the formation of emulsions.

- Clay Stabilizer, to prevent clay swelling.

- Buffer, buffer solution that works to control the price of $\mathrm{pH}$.

- Cross-linker, functions to connect the polymer chain so that it can increase the viscosity of fracturing fluids. 
- Breaker, to reduce the viscosity of the fracturing fluids needed during the flowback process by breaking the polymer chain.

\subsubsection{Proppant}

Proppant is a booster material that serves as a buffer fracture that is formed so that the fractures are not closed again due to closure pressure when pumping is stopped and is expected to be a good flow media for the fluid produced from the formation.

If the proppant experiences stress that exceeds its strength, crushing will occur and will be detrimental in terms of productivity. The harder a formation is, the harder the proppant is needed. Besides, errors in the selection of proppants can affect the success of hydraulic fracturing projects, in this case the selection of proppants depends on the size, distribution (uniform / not), roundness (surface smoothness) and sphericity (spherical shape).

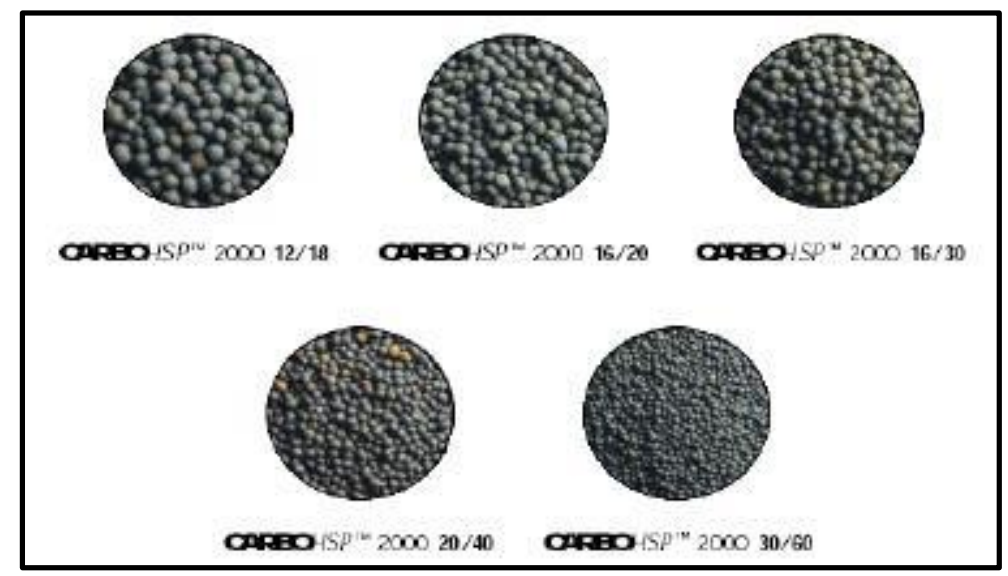

Figure 2.1. Proppant Variations in Various Sizes

Figure 2.1. is a variation of proppant of various sizes, ranging from $12 / 18$ to $30 / 60$. Where the greater the size of proppant grains, the conductivity will be even greater. The number $12 / 18$ is the size of the mesh from 12 to 18 . The mesh is a measure of the number of a net or gauze on an area of 1 inch square. Mesh 12 has the meaning that there are 12 holes in the net / gauze area of 1 inch, and so on.

Some types of proppants commonly used are:

- Sand, based on measured physical properties, sand can be divided into very good conditions, good, and below standard. The best class by API standard is premium sands originating from Illinois, Minnesota, and Wisconsin. Usually called "Northern Sand", "White Sand", "Ottawa Sand", or "Jordan Sand". A good class comes from Hickory Sandstone in the Brady, Texas area, which has a darker color than Ottawa sands. Generally called "Brown Sand", "Braddy Sand", or "Hickory Sand". Its specific gravity is close to 2.65. One of the advantages of this group of sand compared to Ottawa sand is the cheaper price.

- Resin Coated Sand, a resin layer will make sand have a flatter surface (not sharp), so that the load received will be distributed more evenly in each part. When the proppant granules are destroyed because they are unable to withstand the load it receives, the crushed granules will remain attached and not be swept away by the fluid flow due to the presence of a resin layer.

- Ceramic, consisting of low density ceramic, intermediate ceramic. This type of low density ceramic can withstand closing pressure (Clossure pressure) to 6000 psi. While the type of intermediate ceramic has a lighter but more expensive type of proppant with the ability to withstand pressures of up to $12000 \mathrm{psi}$, and is commonly used for high temperatures and wells containing H2S.

- Resin Coated Ceramic, is a combination of resin coating and ceramic granules. This type proves better performance. Coated Ceramic resins have a resistance to closure pressure of 15000 psi and temperatures up to $450^{\circ} \mathrm{F}$.

\subsubsection{The Process of Making Hydraulic Fracturing Fluid}

The following are the stages of making fracturing fluid which is done before being injected into the formation.

1. Making base gel in the blender, where the water in the mixing tank is flowed into the blender to be mixed with additives such as $\mathrm{KCl}$ polymer, surfactant, and others. Then the ready-made base gel is accommodated in the mixing tank again.

2. Making crosslinked gel, which is by mixing the base gel from the mixing tank with the addition of onfly (buffer, crosslinker, breaker).

3. Making Slurry, by mixing crosslinked gel with proppant. Or you can also mix the base gel from the mixing tank and proppant from the sand silo grafity feed, on the blender. Then the new fly is injected during slurry 
travel from the blender to the pump. Crosslink time here must be fast, when high pressure must be done. Because if the crosslink time is slow, it will be difficult to flow slurry because the crosslink becomes very heavy.

4. The slurry that has been added onfly is then pumped by a high-pressure fracturing pump to the formation to go through the wellhead.

\subsubsection{Flow Channel Fracturing}

As time goes by, technology will increasingly develop. Same thing with this fracturing technology. Not long ago a fracturing method, called Flow Channel Fracturing, emerged.

Flow Channel Fracturing is a fracturing process by making a network around the proppant granules to form proppant pillars, so that a path is formed for the fluid to flow more easily.

Figure 2.2. shows a picture of the difference between conventional fracturing (left) and flow channel fracturing (right).

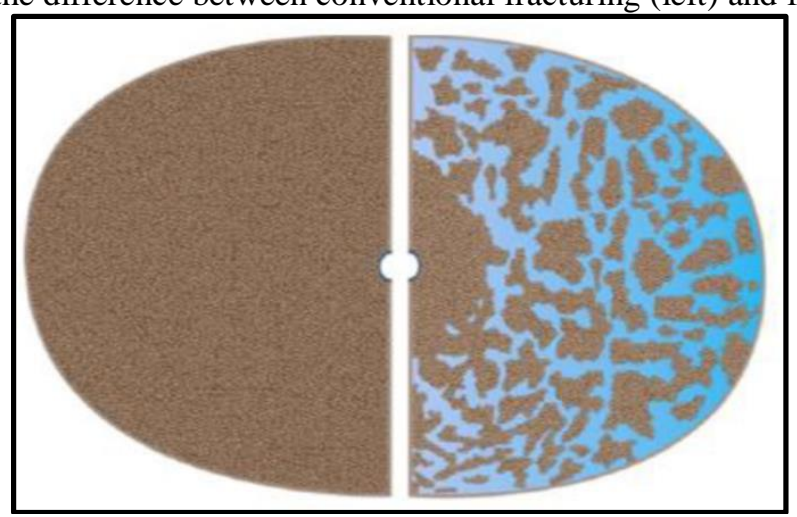

Figure 2.2. Conventional Hydraulic Fracturing vs Flow Channel Fracturing

This Flow Channel Fracturing is claimed to have advantages that can make fracture length more effective, reduce proppant usage, and can increase production.

Several companies that have implemented this method as a mainstay in fracturing operations, including Baker Hughes with EC (Enhanced Conductivity) Prime and Schlumberger with HiWay Fracturing.

Although both use the flow channel method, each company has different characteristics. Seen in Graph 2.1 and Graph 2.2. regarding the pump schedule scheme between conventional fracturing, EC Prime, and HiWay Fracturing.

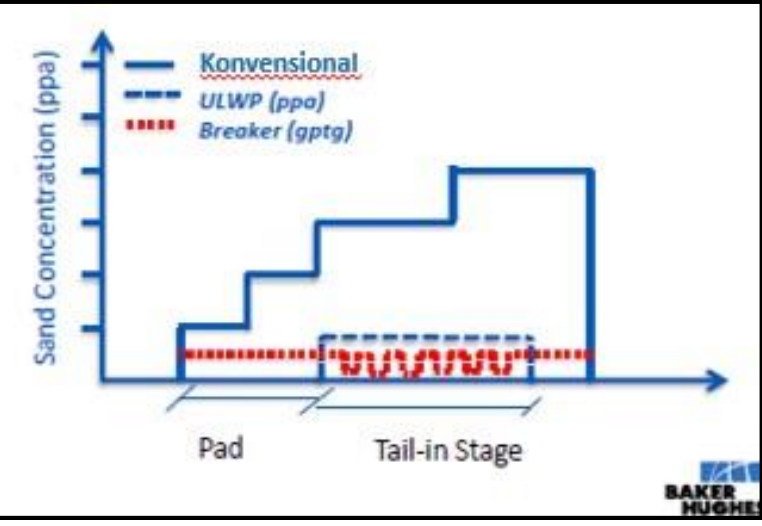

Graph 2.2. Conventional Hydraulic Fracturing vs EC Prime 


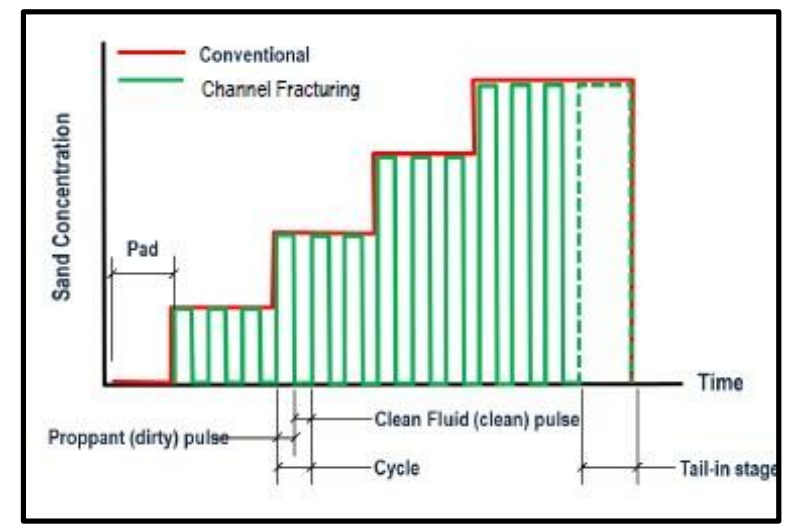

Graph 2.3. Conventional Hydraulic Fracturing vs HiWay

In conventional fracturing, the concentration of proppant will increase over time.

At EC Prime, Baker Hughes places more emphasis on the differences in the viscosity of the fracturing fluid, namely thick fluid and thin fluid. Where this thin fluid will cut thick fluid later because the viscosity of thin fluid is low so it has high mobility to cut thick fluid. In this Prime EC operation Ultra Light Weight Proppant (ULWP) is also used, which serves to hold the channel from being closed again. The use of ULWP in EC Prime operations is only used in the tail in the stage process, ie when thick fluid and thin fluid are injected. This thick fluid and thin fluid grouping is based on a lot of concentrations of additives such as breakers, buffers, and crosslinkers found in slurry.

As for HiWay Fracturing, Schlumberger focuses on the concentration of proppants injected in each cycle. Where in one cycle there are two kinds of fluid that are injected, namely dirty fluid and clean fluid. Dirty fluid is a fracturing fluid that is injected using an additional proppant. While clean fluid is a fracturing fluid without proppant.

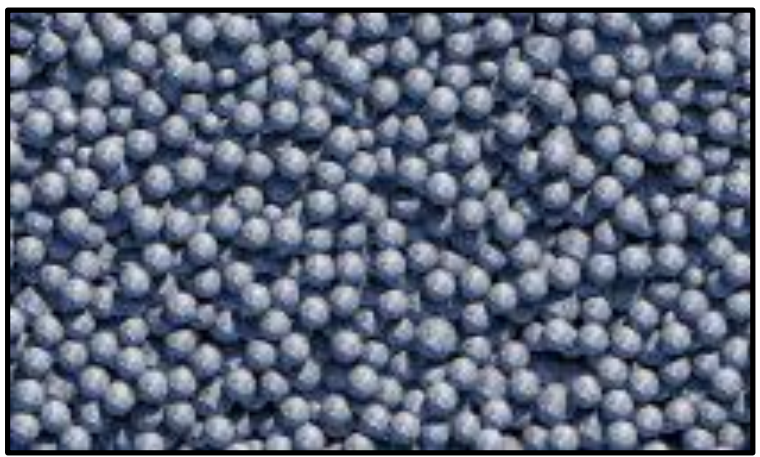

Figure 2.3. Conventional Hydraulic Fracturing

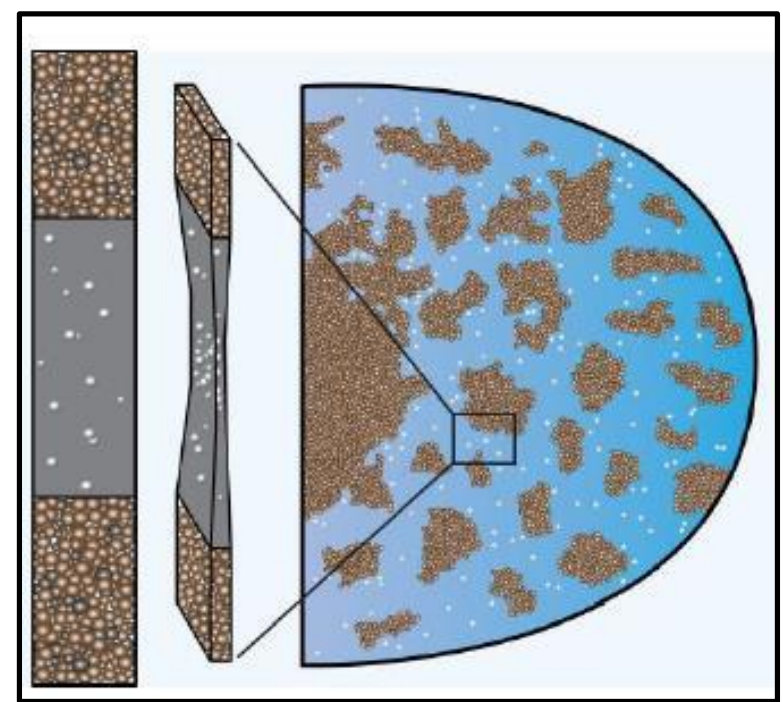

Figure 2.4. EC Prime Pillar Fracturing 


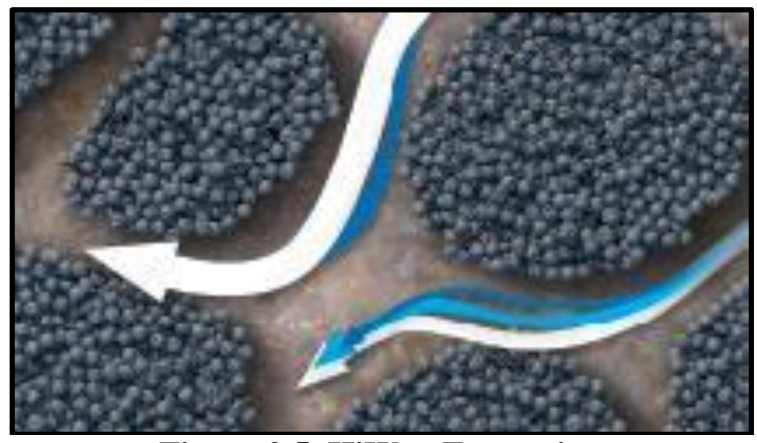

Figure 2.5. HiWay Fracturing

Figure 2.3. up to Figure 2.5. is an illustration between conventional fracturing, EC Prime Fracturing, and HiWay Fracturing. For conventional fracturing, visible formation is fully fractured with proppants. For EC Prime fracturing, seen in the channel between the proppant pillars that are formed there is a ULWP which aims to hold the channel from being closed again. Unlike HiWay Fracturing where there is no ULWP on the channel.

This Flow Channel Fracturing will work optimally when applied to sandstone, batbonbonate, and claystone formations in both oil wells and gas wells.

\section{RESEARCH METHODS}

The stages of this research consist of literature studies, field observations by collecting primary data and secondary data to process existing data. This study discusses the analysis of differences between conventional hydraulic fracturing and flow-channel fracturing.

\section{DISCUSSION}

Hydraulic fracturing is a well stimulation technique for breaking rock layers by injecting fracture fluid into the formation with the condition of injection pressure will be greater than the formation pressure value. In hydraulic fracturing, the injected fracture fluid must be accompanied by a proppant material that serves as a buffer so that the fracture formed does not close again.

Hydraulic fracturing operation can be done in two ways namely the conventional method and the flow channel fracturing method. What distinguishes the two is the resulting fracture shape, fracturing fluid injection pattern, and the amount of proppant used. The difference in fracture forms in conventional operations with flow channel fracturing can be seen in Figure 2.2. wherein conventional operations, the fracture form will be full of proppant, whereas in the fracturing flow channel the fracture form will form pillars. Flow channel fracturing operations have various names according to the company that applies the method, such as EC Prime on Baker Hughes and HiWay Fracturing at Schlumberger, then the fracturing fluid injection pattern and the number of proppants used will vary according to the provisions of each company.

In conventional operations, proppant concentration will increase over time. At EC Prime Fracturing, Baker Hughes places more emphasis on the difference in viscosity of his fracturing fluid, namely thick and thin. Where is this thin fluid that will cut thick fluid, because the viscosity is low so the mobility is high. EC Prime Fracturing also uses Ultra LightWeight Proppant (ULWP), to hold the channel from being closed again. In Graph 2.2. visible ULWP is only used when the tail in stage only when thick \& thin fluid is injected. Whereas the thick-thin fluid is played at many concentrations of additives such as breakers, buffers, and crosslinkers. As for HiWay Fracturing, Graph 2.3., Schlumberger focuses on the concentration of proppant injected in each cycle. Where in one cycle two kinds of fluid are injected, namely dirty fluid and clean fluid. Dirty fluid here means fracturing fluid that is injected using an additional proppant. Whereas clean fluid means fracturing fluid without proppant.

Based on case studies conducted in various fields, the application of flow channel fracturing is considered effective because it is proven to be able to optimally increase the amount of hydrocarbon fluid production.

\section{CONCLUSION}

Based on the analysis conducted, it can be concluded that:

1. Hydraulic fracturing is a well stimulation technique for breaking rock layers by injecting fracture fluid into the formation (Injection> Prf).

2. In hydraulic fracturing proppant is used as a booster material so that the fracture does not close again.

3. Hydraulic fracturing operation can be done in two ways, namely the conventional method and the flow channel fracturing method. 
4. What distinguishes conventional methods of hydraulic fracturing and flow channel fracturing is the resulting fracture form, fracturing fluid injection pattern, and the number of proppants used.

5. In conventional Hydraulic Fracturing the shape of the fracture is widened because the proppant that is injected will fill the entire fracture space, while the fracturing flow channel of the fracture will form pillars thus leaving a path for hydrocarbon fluid to flow.

6. For injection patterns and the number of proppants used, in conventional Hydraulic Fracturing fluid will be injected just like that with the pressure already obtained at the breakdown test and step rate test, while in the Hydraulic Fracturing flow channel different injection patterns are used such as thick-thin patterns for EC Prime of Baker Hughes with a higher and more varied number of proppants (also use ULWP), and cycle-based patterns on the Schlumberger HiWay fracturing which emphasizes dirty fluid injection (a mixture of fracturing fluid and proppant) and clean fluid (only fracturing fluid) alternately.

\section{REFERENCES}

Abdelhamid, M.S.A., Marouf, M., Kamal, Y., Shaaban, A., Mathur, A., Yosry, M., et al.: "Field Development Study: Channel Fracturing Technique Combined with Rod-Shaped Proppant Improves Production, Eliminates Proppant Flow Back Issues and Screen Outs in the Western Desert, Egypt," SPE paper 164753, presented at the North Africa Technical Conference and Exhibition, Cairo, Egypt, April 15-17, 2013.

Medvedev, A.V., Kraemer, C.C., Pena, A.A. and Raju Panga, M.K.: “On the Mechanisms of Channel Fracturing,” SPE paper 163836, presented at the SPE Hydraulic Fracturing Technology Conference, The Woodlands, Texas, February 46, 2013.

Kayumov, R., Klyubin, A., Konchenko, A., Yudin, A., Khalzov, A., Firsov, V., et al.: "Channel Fracturing Enhanced by Unconventional Proppant Increases Effectiveness of Hydraulic Fracturing in Devonian Formations of Russia's Oil Fields," IPTC paper 17409, presented at the International Petroleum Technology Conference, Doha, Qatar, January 1922, 2014.

Valenzuela, A., Guzman, J., Moreno, S.S., Garcia Mondragon, G., Gutierrez Rodruigues, L.A., Exler, V.A., et al.: "Field Development Study: Channel Fracturing Increases Gas Production and Improves Polymer Recovery in Burgos Basin, Mexico North," SPE paper 152112, presented at the SPE Hydraulic Fracturing Technology Conference, The Woodlands, Texas, February 6-8, 2012.

Gillard, M.R., Medvedev, O.O., Hosein, P.R., Medvedev, A., Peñacorada, F. and d'Huteau, E.: “A New Approach to Generating Fracture Conductivity," SPE paper 135034, presented at the SPE Annual Technical Conference and Exhibition, Florence, Italy, September 19-22, 2010.

Barry B, Jack E, Mark M, Hugo M, Ken N, et al. (1992) Cracking Rock: Progress in Fracture Treatment Design. Oilfield Review 4: 4-17.

Les B, Joel Le C, David R, Sarver KT, Birk GW, et al. (2005) The Source for Hydraulic Fracture Characterization. Oilfield Review 17: 42-57.

http://www.csur.com/images/CSUG_publications/CSUG_HydraulicFrac_Brochure.pdf

http://www.slb.com/resources/publications/industry_articles/stimulation/201212_harts_hydraulic_fracturing_key_pla yers.aspx

https://www.propublica.org/special/hydraulic-fracturing-national http://www.slb.com/services/completions/stimulation/sandstone/hiway channel fracturing.aspx https://www.bhge.com/sites/default/files/2017-10/EC-Prime-Enhanced-Conductivity-Fracturing-Service-slsh.pdf www.halliburton.com/public/pinnacle/contents/Case_Histories/web/H08441.pdf www.slb.com/HiWAY 